\title{
Bacteriophage Lysins as Effective Antibacterials
}

\author{
Vincent A. Fischetti, Ph.D. \\ Professor and Head, Laboratory of Bacterial Pathogenesis, Rockefeller University, 1230 York \\ Avenue, New York, NY 10021, Pho: 212-327-8166, Fax: 212-327-7584
}

\section{Summary}

Lysins are highly evolved enzymes produced by bacteriophage ( phage for short) to digest the bacterial cell wall for phage progeny release. In gram-positive bacteria, small quantities of purified recombinant lysin added externally results in immediate lysis causing log-fold death of the target bacterium. Lysins have been used successfully in a variety of animal models to control pathogenic antibiotic resistant bacteria found on mucosal surfaces and infected tissues. The advantages over antibiotics are their specificity for the pathogen without disturbing the normal flora, the low chance of bacterial resistance to lysins, and their ability to kill colonizing pathogens on mucosal surfaces, a capacity previously unavailable. Thus, lysins may be a much needed anti-infective in an age of mounting antibiotic resistance.

\section{Keywords}

Phage; Bacteriophage; Cell wall; Gram-positive bacteria; Infection; Lysin; Lytic enzymes; Mucosal colonization; Pathogens; Peptidoglycan

\section{Background}

Bacteriophages or phages are viruses that specifically infect bacteria. After replication inside its bacterial host the phage is faced with a problem, it needs to exit the bacterium to disseminate its progeny phage. To solve this, double-stranded DNA phages have evolved a lytic system to weaken the bacterial cell wall resulting in bacterial lysis. Phage lytic enzymes or lysins are highly efficient molecules that have been refined over millions of years for this very purpose. These enzymes target the integrity of the cell wall, and are designed to attack one of the four major bonds in the peptidoglycan. With few exceptions, [1], lysins do not have signal sequences, so they are not translocated through the cytoplasmic membrane to attack their substrate in the peptidoglycan, this movement is controlled by a second phage gene product in the lytic system, the holin [2]. During phage development in the infected bacterium, lysin accumulates in the cytoplasm in anticipation of phage maturation. At a genetically specified time, holin molecules are inserted in the cytoplasmic membrane forming patches, ultimately resulting in generalized membrane disruption [3], allowing the cytoplasmic lysin to access the peptidoglycan, thereby causing cell lysis and the release of progeny phage [2]. In contrast to large DNA phage, small RNA and DNA phages use a different release strategy. They call upon a phage-encoded proteins to interfere with bacterial host enzymes responsible for peptidoglycan biosynthesis [4] [5] resulting in misassembled cell walls and ultimate lysis.

Email: vaf@ rockefeller.edu.

Publisher's Disclaimer: This is a PDF file of an unedited manuscript that has been accepted for publication. As a service to our customers we are providing this early version of the manuscript. The manuscript will undergo copyediting, typesetting, and review of the resulting proof before it is published in its final citable form. Please note that during the production process errors may be discovered which could affect the content, and all legal disclaimers that apply to the journal pertain. 
Scientists have been aware of the lytic activity of phage for nearly a century, and while whole phage have been used to control infection [6], not until recently have lytic enzymes been exploited for bacterial control in vivo [7;8;9]. One of the main reasons that such an approach is now even being considered is the sharp increase in antibiotic resistance among pathogenic bacteria. Current data indicate that lysins work only with gram-positive bacteria, since they are able to make direct contact with the cell wall carbohydrates and peptidoglycan when added externally, whereas the outer membrane of gram-negative bacteria prevents this interaction. This review will outline the remarkable potency these enzymes have in killing bacteria both in vitro and in vivo.

The great majority of human infections (viral or bacterial) begin at a mucous membrane site (upper and lower respiratory, intestinal, urogenital, and ocular). In addition, the human mucous membranes are the reservoir (and sometimes the only reservoir) for many pathogenic bacteria found in the environment (i.e., pneumococci, staphylococci, streptococci) some of which are resistant to antibiotics. In most instances, it is this mucosal reservoir that is the focus of infection in the population [10-12]. To date, except for polysporin and mupirocin ointments, which are the most widely used topically, there are no anti-infectives that are designed to control colonizing pathogenic bacteria on mucous membranes [13]. Current practice is to wait for infection to occur before treating. Because of the fear of increasing the resistance problem, antibiotics are not indicated to control the carrier state of disease bacteria. It is acknowledged however, that by reducing or eliminating this human reservoir of pathogens in the community and controlled environments (i.e., hospitals and nursing homes), the incidence of disease will be markedly reduced [10;13]. Towards this goal, lysins have been developed to prevent infection by safely and specifically destroying disease bacteria on mucous membranes. For example, based on extensive animal results, enzymes specific for $S$. pneumoniae and $S$. pyogenes, may be used nasally and orally to control these organisms in the community as well as in nursing homes and hospitals to prevent or markedly reduce serious infections caused by these bacteria. This has been accomplished by capitalizing on the efficiency by which phage lysins kill bacteria [14]. Like antibiotics, which are used by bacteria to control the organisms around them in the environment, phage lysins are the culmination of millions of years of development by the bacteriophage in their association with bacteria. Specific lysins have now been identified and purified that are able to kill specific gram-positive bacteria seconds after contact $[7 ; 15]$. For example, nanogram quantities of lysin could reduce $10^{7}$ S. pyogenes by $>6$ logs seconds after enzyme addition. No known biological compounds, except chemical agents, kill bacteria this quickly.

\section{Structure}

Lysins from DNA-phage that infect gram-positive bacteria are generally between $25-40 \mathrm{kDa}$ in size except the PlyC for streptococci which is $114 \mathrm{kDa}$. This enzyme is unique because it is composed of two separate gene products, PlyCA and PlyCB. Based on biochemical and biophysical studies, the catalytically active PlyC holoenzyme is composed of eight PlyCB subunits for each PlyCA [16] A feature of all other gram-positive phage lysins is their twodomain structure (Figure 1) [17;18]. With some exceptions, the N-terminal domain contains the catalytic activity of the enzyme. This activity may be either an endo- $\beta-\mathrm{N}$ -

acetylglucosaminidase or $\mathrm{N}$-acetylmuramidase (lysozymes), both of which act on the sugar moiety of the bacterial wall, an endopeptidase which acts on the peptide moiety, or an Nacetylmuramoyl-L-alanine amidase (or amidase), which hydrolyzes the amide bond connecting the glycan strand and peptide moieties [14;19]. Recently an enzyme with $\gamma$-D-glutaminyl-Llysine endopeptidase activity has also been reported [20]. In some cases, particularly staphylococcal lysins, two and perhaps even three different catalytic domains may be linked to a single binding domain [21]. The C-terminal cell binding domain (termed the CBD domain) on the other hand binds to a specific substrate (usually carbohydrate) found in the cell wall of 
the host bacterium [22] [23] [24]. Efficient cleavage requires that the binding domain bind to its cell wall substrate, offering some degree of specificity to the enzyme since these substrates are only found in enzyme-sensitive bacteria. The first complete crystal structure for the free and choline bound states of the Cpl-1 lytic enzyme has recently been published [25]. As suspected, the data suggest that choline recognition by the choline binding domain of Cpl-1may allow the catalytic domain to be properly oriented for efficient cleavage. An interesting feature of this lysin is its hairpin conformation suggesting that the two domains interact with each other prior to the interaction of the binding domain with its substrate in the bacterial cell wall. Other lytic enzymes need to be crystallized to determine if this is a common feature of all lysins.

When the sequences between lytic enzymes of the same enzyme class were compared, it showed high sequence homology within the $\mathrm{N}$-terminal catalytic region and very little homology within in the C-terminal cell binding region. It seemed counterintuitive that the phage would design a lysin that was uniquely lethal for its host organism, however as more is learned more about how these enzymes function, a possible reason for this specificity became apparent (see below, Resistance). However, because of the specificity, enzymes that spilled out after cell lysis had a good chance of killing potential bacterial hosts in the vicinity of the released phage progeny. Because of this, the enzymes have evolved to bind to their cell wall binding domains at a high affinity [26] to limit the release of free enzyme.

Because of their domain structure, it seemed plausible that different enzyme domains could be swapped resulting in lysins with different bacterial and catalytic specificities. This was actually accomplished by excellent detailed studies of Garcia and colleagues [18;27], in which the catalytic domains of lytic enzymes for $S$. pneumoniae phage could be swapped resulting in a new enzyme having the same binding domain for pneumococci, but able to cleave a different bond in the peptidoglycan. This capacity allows for enormous potential in creating designer enzymes with high specificity and equally high cleavage potential.

Though uncommon, introns have been associated with certain lysins. For example, 50\% of $S$. thermophilus phages have been reported to have their lysin gene interrupted by a self-splicing group I intron [28]. This also appears to be the case for a $S$. aureus lytic enzyme [29] and perhaps the $\mathrm{C} 1$ lysin for group $\mathrm{C}$ streptococci [30]. While introns have been previously reported in phage genes, they have rarely been identified in the host genome [31;32].

\section{Mode of Action}

Thin section electron microscopy of lysin-treated bacteria reveals that lysins exert their lethal effects by forming holes in the cell wall through peptidoglycan digestion. The high internal pressure of bacterial cells (roughly $3-5$ atmospheres) is controlled by the highly cross-linked cell wall. Any disruption in the wall's integrity will result in the extrusion of the cytoplasmic membrane and ultimate hypotonic lysis (Figure 2). Catalytically, a single enzyme molecule should be sufficient to cleave an adequate number of bonds to kill an organism, however, it is uncertain at this time whether this theoretical limit is possible. The reason comes from the work of Loessner [26], showing that a listeria phage enzyme had a binding affinity approaching that of an IgG molecule for its substrate, suggesting that phage enzymes, like cellulases [33] are one-use enzymes, likely requiring several molecules attacking a local region to sufficiently weaken the cell wall.

\section{Lysin Efficacy}

Generally lysins only kill the species (or subspecies) of bacteria from which they were produced. For instance, enzymes produced from streptococcal phage kill certain streptococci, and enzymes produced by pneumococcal phage kill pneumococci [15],[7]. Specifically, a lysin 
from a group C streptococcal phage (PlyC) will kill group C streptococci, as well as groups A and E streptococci, the bovine pathogen $S$. uberis and the horse pathogen, S. equi, but essentially no effect on streptococci normally found in the oral cavity of humans and other gram-positive bacteria. Similar results are seen with a pneumococcal-specific lysin, however in this case, the enzyme was also tested against strains of penicillin-resistant pneumococci and the killing efficiency was the same. Unlike antibiotics, which are usually broad spectrum and kill many different bacteria found in the human body, some of which are beneficial, lysins may be identified which kill only the disease organism with little to no effect on the normal human bacterial flora. In some cases however, phage enzymes may be identified with broad lytic activity. For example, an enterococcal phage lysin has recently been reported to not only kill enterococci but a number of other gram-positive pathogens such as $S$. pyogenes, group B streptococci and Staphylococcus aureus, making it one of the broadest acting lysins identified [34]. However, its activity for these other pathogens was lower than for enterococci.

An important lysin with respect to infection control is a lysin directed to Staphylococcus aureus [35-39]. However in most cases these enzymes show low activity or are difficult to produce large quantities. In one recent publication [35], an staphylococcal enzyme was described that could be easily produced recombinantly and had a significant lethal effect on methicillin resistant Staphylococcus aureus (MRSA) both in vitro and in a mouse model. In the animal experiments the authors show that the enzymes may be used to decolonize staphylococci from the nose of the mice as well as protect the animals from an intraperitoneal challenge with MRSA. However, in the latter experiments, the best protection was observed if the lysine was added up to 30 minutes after the MRSA.

\section{Antibiotic and Lysin Synergy}

Several lysins have been identified from pneumococcal bacteriophage which are classified into two groups: amidases, and lysozymes. Exposure of pneumococci to either of these enzymes leads to efficient lysis. Both enzymes have very different $\mathrm{N}$-terminal catalytic domains but share a similar C-terminal choline cell binding domain. These enzymes were tested to determine whether their simultaneous use is competitive or synergistic [40].

To accomplish this, three different methods of analyses were used to determine synergy, time kill in liquid, disk diffusion and checkerboard broth microdilution analysis. All three are standard methods used in the antibiotic industry to determine synergy [41]. In all three assays, the results revealed a clear synergistic effect in the efficiency of killing when both enzymes were used [40]. In vivo, the combination of two lysins with different peptidoglycan specificities were found to be more effective in protecting against disease than each of the single enzymes [40] [42]. Thus, in addition to more effective killing, the application of two different lysins may significantly retard the emergence of enzyme-resistant mutants.

When the pneumococcal lysin Cpl-1 was used in combination with certain antibiotics a similar synergistic effect was seen. Cpl-1 and gentamicin were found to be increasingly synergistic in killing pneumococci with a decreasing penicillin MIC, while Cpl-1 and penicillin showed synergy against an extremely penicillin-resistant strain [43]. Synergy was also observed with a staphylococcal-specific enzyme and glycopeptide antibiotics [35]. Thus, the right combination of enzyme and antibiotic could help in the control of antibiotic resistant bacteria as well as reinstate the use of certain antibiotics for which resistance has been established.

\section{Effects of Antibodies}

The pharmacokenetics of lysins like other foreign proteins delivered systemically to animals is about 20 minutes [8]. Thus, if lysins are to be used systemically, they will need to be modified to extend their half-life, or they need to be delivered frequently or by IV infusion. An additional 
concern in the use of lysins is the development of neutralizing antibodies which could reduce the in vivo levels of enzyme during treatment. Unlike antibiotics, which are small molecules that are not generally immunogenic, enzymes are proteins that stimulate an immune response, when delivered mucosally or systemically, which could interfere with the lysin's activity. To address this, rabbit hyperimmune serum raised against the pneumococcal-specific enzyme Cpl-1 was assayed for its effect on lytic activity [8]. It was found that highly immune serum slows, but does not block the lytic activity of Cpl-1. When similar in vitro experiments were performed with antibodies directed to an anthrax- and an S. pyogenes-specific enzyme, similar results were obtained (unpublished data). These results were also verified with a staphylococcal-specific lysin [35].

To test the relevance of this in vivo, mice that received three intravenous doses of the Cpl-1 enzyme had tested positive for IgG against Cpl-1 in 5 of 6 cases with low but measurable titers of about 1:10. These vaccinated and naïve control mice were then challenged intravenously with pneumococci and then treated by the same route with $200 \mu \mathrm{g} \mathrm{Cpl-1}$ after 10 hours. Within a minute, the treatment reduced the bacteremic titer of Cpl-1-immunized mice to the same degree as the naive mice, supporting the in vitro data that antibody to lysins have little to no neutralizing effect. A similar experiment by Rashel with a staphylococcal enzyme [35], showed the same result and that the animals injected with lysin multiple time exhibited no adverse events.

This unexpected effect may be partially explained if the binding affinity of the enzyme for its substrate in the bacterial cell wall is higher than the antibody's affinity for the enzyme. This is supported by the results of Loessner [26], showing that the cell wall binding domain of a listeria-specific phage enzyme binds to its wall substrate at the affinity of an IgG molecule (nanomolar affinities). However, while this may explain the inability of the antibody to neutralize the binding domain, it does not explain why antibodies to the catalytic domain do not neutralize. Nevertheless, these results are encouraging since it suggests that such enzymes may be used repeatedly in certain situations to control colonizing bacteria on mucosal surfaces in susceptible populations such as hospitals, day care centers and nursing homes, or in blood to eliminate antibiotic resistant bacteria in cases of septicemia and bacteremia.

\section{Animal Models of Infection}

Animal models of mucosal colonization were used to test the capacity of lysins to kill organisms on these surfaces; perhaps the most important use for these enzymes. An oral colonization model was developed for S. pyogenes [7], a nasal model for pneumococci [15], and a vaginal model for group B streptococci [44]. In all three cases, when the animals were colonized with their respective bacteria and treated with a single dose of lysin, specific for the colonizing organism, these organisms were reduced by several logs (and in some cases below the detection limit of the assay) when tested again two to four hours after lysin treatment. These results lend support to the idea that such enzymes may be used in specific high-risk populations to control the reservoir of pathogenic bacteria and thus control disease.

\section{Sepsis, Pneumonia, Endocarditis, and Meningitis}

Similar to other proteins delivered intravenously to animals and humans, lysins have a short half life (c.a. 15-20 minutes) [8]. However, the action of lysins for bacteria is so rapid, that this may be sufficient time to observe a therapeutic effect [8;42]. Mice intravenously infected with type $14 \mathrm{~S}$. pneumoniae and treated 1 hour later with a single bolus of $2.0 \mathrm{mg}$ of Cpl-1 survived through the $48 \mathrm{~h}$ endpoint, whereas the median survival time of buffer-treated mice was only 25 hours, and only $20 \%$ survival at $48 \mathrm{~h}$ (Figure 3 ). Blood and organ cultures of the euthanized surviving mice showed that only one Cpl-1-treated animal was totally free of infection at $48 \mathrm{~h}$, suggesting that multiple enzyme doses or a constant infusion of enzyme would 
be required to eliminate the organisms completely in this application. Similar results were obtained when animals were infected and treated intraperitoneally with lysin [42] [35]. Because of lysin's short half-life, it may be necessary to modifiy the lysins with polyethylene glycol or the Fc region of IgG, to extend the residence time in vivo to several hours [45]. In recent studies, phage lysins have also been shown to be successful in the treatment of meningitis by directly adding the lysin directly to the brain intrathecally. [46] and endocarditis by delivering the lysin intravenously by constant IV infusion [47]. Both these applications would also benefit from modified long-acting lysins.

The ultimate challenge for lysins would be to determine whether they are able to cure an established infection. To approach this, a mouse pneumonia model was developed in which mice were transnasally infected with pneumococci and treated with Cpl-1 by repeated intraperitoneal injections after infection was established (Witzenrath et al, in press). From a variety of clinical measurements, as well as morphologic changes in the lungs, it was shown that at 24 hours mice suffered from severe pneumonia. When treatment was initiated at $24 \mathrm{~h}$ and every 12 hours thereafter, $100 \%$ of the mice survived otherwise fatal pneumonia and showed rapid recovery. Cpl-1 dramatically reduced pulmonary bacterial counts, and prevented bacteremia.

Using lysins systemically to kill bacteria could result in an increase in cytokine production as a result of bacterial debris being release. In one study to address this issue [47], untreated pneumococcal endocarditis induced the release of interleukin- $1 \alpha$ (IL-1 $\alpha$ ), IL-1 $\beta$, IL-6, IL-10, gamma interferon, and tumor necrosis factor, but not IL-2, IL-4, or granulocyte-macrophage colony- stimulating factor. However, in a mouse model of pneumonia (Witzenrath et al, In press) Witzenrath showed that transnasal infection with pneumococci caused an increase of proinflammatory cytokines and chemokines within 36h. However, treatment with Cpl-1 was associated with reduced synthesis of IL- $1 \beta$, IL- 6 , and the chemokines KC, Mip- $1 \alpha$, and MCP-1, as well as G-CSF in the lung. In addition, decreases were observed in plasma concentrations of IL-6, KC, and Mip- $1 \alpha$, and MCP-1, G-CSF, and IFN $\gamma$ concentrations. Pulmonary and systemic IL-10 synthesis was only found in septic animals 60h after infection, and was completely prevented by Cpl-1 treatment. The reason for this difference has not been determined as yet, however it may depend on the amount of lysin used for the treatments. It is possible that in the former study, in which the animals were treated with a constant IV infusion of lysin that the high concentration of the enzyme resulted in the fragmentation of the bacterial cell wall while in the second study, enzyme was delivered in $12 \mathrm{~h}$ intervals resulting in producing holes in the bacterial cell wall without forming wall pieces which are clearly more inflammatory [48] [49].

Since lysins are proteins it is unlikely that they are able to enter cells. However, there are no publications to date that address the issue of the effects of lysins on intracellular bacteria.

\section{Anthrax}

Because lysins are able to kill pathogenic bacteria rapidly they may be a valuable tool in controlling biowarfare bacteria. To determine the feasibility of this approach a lytic enzyme was identified from the gamma phage, a lytic phage that is highly specific for Bacillus anthracis [50]. The gamma lysin, termed PlyG, was purified to homogeneity by a two-step chromatography procedure and tested for its lethal action on gamma phage-sensitive bacilli [9]. Three seconds after contact, as little as 100 units (about $100 \mathrm{ug} / \mathrm{ml}$ ) of PlyG mediated a 5,000 -fold decrease in viable counts of a suspension of $\sim 10^{7}$ bacilli. When the enzyme was then tested against ten $B$. anthracis strains from different clonal types isolated worldwide, all could be killed. In addition, the PlyG lysin was also lethal for five mutant $B$. anthracis strains lacking either capsule or toxin plasmids. 
Based on physiological characteristics, sensitivity to gamma phage and mouse lethality, a strain of B. cereus was identified that is closely related to $B$. anthracis. In vivo experiments revealed that when $10^{7}$ of these organisms were administered intraperitoneally (IP) to 10 mice, all except one died of a rapidly fatal septicemia within four hours (10\% survival). When a second set of 18 mice were also challenged IP with these bacilli, but given a single 100 ug dose of PlyG 15 minutes later by the same route, only five animals died (72\% survival) and in three of these animals death was delayed $>24$ hours. It is anticipated that based on the half-life of lysins (see above) higher doses, multiple doses, or constant IV infusion of lysin will result in increased survival.

Because the treatment window for individuals exposed to anthrax is about $48 \mathrm{hrs,} \mathrm{PlyG} \mathrm{may}$ be used intravenously in post exposure individuals to increase the treatment window beyond the $48 \mathrm{~h}$ period. This would allow more time to test the infecting bacillus for its antibiotic resistance spectrum before treatment.

\section{Bacterial resistance to lysins}

Exposure of bacteria grown on agar plates to low concentrations of lysin did not lead to the recovery of resistant strains even after over 40 cycles. Organisms in colonies isolated at the periphery of a clear lytic zone created by a 10 ul drop of dilute lysin on a lawn of bacteria always resulted in enzyme sensitive bacteria. Enzyme resistant bacteria could also not be identified after $>10$ cycles of bacterial exposure to low concentrations of lysin (from 5-20 units) in liquid culture $[9 ; 15]$. These results may be explained by the fact that the cell wall receptor for the pneumococcal lysin is choline [51], a molecule that is essential for pneumococcal viability. While not yet proven, it is possible that during a phage's association with bacteria over the millennia, to avoid becoming trapped inside the host, the binding domain of their lytic enzymes has evolved to target a unique and essential molecule in the cell wall, making resistance to these enzymes a rare event. Since through evolution the phage has performed the "high throughput" analysis to identify the "Achilles heel" of these bacteria, we may take advantage of this by identifying the pathway for the synthesis of the lytic enzyme's cell wall receptor and identify inhibitors for this pathway. This would theoretically result in lead compounds that may be used to identify new anti-microbials that would be difficult to become resistant against.

\section{Conclusion}

Lysins are a new reagent to control bacterial pathogens, particularly those found on the human mucosal surface. For the first time we may be able to specifically kill pathogens on mucous membranes without affecting the surrounding normal flora thus reducing a significant pathogen reservoir in the population. Since this capability has not been previously available, its acceptance may not be immediate. Nevertheless, like vaccines, we should be striving to developing methods to prevent rather than treat infection. Whenever there is a need to kill bacteria, and contact can be made with the organism, lysins may be freely utilized. Such enzymes will be of direct benefit in environments where antibiotic resistant gram-positive pathogens are a serious problem, such as hospitals, day care centers and nursing homes. The lysins isolated thus far are remarkably heat stable (up to $60 \mathrm{C}$ ) and are relatively easy to produce in a purified state and in large quantities, making them amenable to these applications. The challenge for the future is to use this basic strategy and improve upon it, as was the case for second and third generation antibiotics. Protein engineering, domain swapping and gene shuffling all could lead to better lytic enzymes to control bacterial pathogens in a variety of environments. Since it is estimated that there are $10^{31}$ phage on earth, the potential to identify new lytic enzymes as well as those that kill gram-negative bacteria is enormous. Perhaps some 
day phage lytic enzymes will be an essential component in our armamentarium against pathogenic bacteria.

\section{Acknowledgements}

I wish to acknowledge the members of my laboratory who are responsible for much of the phage lysin work, Qi Chang, Mattias Collin, Anu Daniel, Sherry Kan, Jutta Loeffler, Daniel Nelson, Jonathan Schmitz, Raymond Schuch, and Pauline Yoong, and with the excellent technical assistance of Peter Chahales, Adam Pelzek, Rachel Shively, Mary Windels, and Shiwei Zhu. I am indebted to my collaborators Philippe Moreillon, Stephen Leib and Martin Witzenrath for their excellent work with the lysins in their model systems. I also wish to thank Abraham Turetsky at the Aberdeen Proving Grounds and Leonard Mayer of the CDC for testing the gamma lysin against authentic B. anthracis strains and Richard Lyons and Julie Lovchik for the animal protection studies with anthrax. Supported by DARPA and USPHS Grants AI057472 and AI11822.

\section{Reference List}

1. Loessner MJ, Maier SK, Daubek-Puza H, Wendlinger G, Scherer S. Three Bacillus cereus bacteriophage endolysins are unrelated but reveal high homology to cell wall hydrolases from different bacilli. J Bacteriol 1997;179:2845-2851. [PubMed: 9139898]

2. Wang I-N, Smith DL, Young R. Holins: the protein clocks of bacteriophage infections. Annu Rev Microbiol 2000;54:799-825. [PubMed: 11018145]

3. Wang I-N, Deaton J, Young R. Sizing the Holin Lesion with an Endolysin-beta-Galactosidase fusion. Journal of Bacteriology 2003;185:779-787. [PubMed: 12533453]

4. Young R, Wang I-N, Roof WD. Phages will out: strategies of host cell lysis. Trends in Micro 2000;8:120-128.

5. Bernhardt TG, Wang IN, Struck DK, Young R. A protein antibiotic in the phage Q-beta virion: diversity in lysis targets. Science 2001;292:2326-2329. [PubMed: 11423662]

6. Matsuzaki S, Rashel M, Uchiyama J, Sakurai S, Ujihara T, Kuroda M, Ikeuchi M, Tani T, Fujieda M, Wakiguchi H, Imai S. Bacteriophage therapy: a revitalized therapy against bacterial infectious diseases. J Infect Chemother 2005;11:211-219. [PubMed: 16258815]

7. Nelson D, Loomis L, Fischetti VA. Prevention and elimination of upper respiratory colonization of mice by group A streptococci by using a bacteriophage lytic enzyme. Proc Natl Acad Sci USA 2001;98:4107-4112. [PubMed: 11259652]

8. Loeffler JM, Djurkovic S, Fischetti VA. Phage lytic enzyme Cpl-1 as a novel antimicrobial for pneumococcal bacteremia. Infect Immun 2003;71:6199-6204. [PubMed: 14573637]

9. Schuch R, Nelson D, Fischetti VA. A bacteriolytic agent that detects and kills Bacillus anthracis. Science 2002;418:884-889.

10. Eiff CV, Becker K, Machka K, Stammer H, Peters G. Nasal carriage as a source of Staphlococcus aureus bacteremia. N Engl J Med 2001;344:11-16. [PubMed: 11136954]

11. Coello R, Jimenez J, Garcia M, Arroyo P, Minguez D, Fernandez C, Cruzet F, Gaspar C. Prospective study of infection, colonization and carriage of methicillin-resistant Staphylococcus aureus in an outbreak affecting 990 patients. Eur J Clin Microbiol Infect Dis 1994;13:74-81. [PubMed: 8168567]

12. de Lencastre H, Kristinsson KG, Brito-Avo A, Sanches IS, Sa-Leao R, Saldanha J, Sigvaldadottir E, Karlsson S, Oliveira D, Mato R, de Sousa MA, Tomasz A. Carriage of respiratory tract pathogens and molecular epidemiology of Streptococcus pneumoniae colonization in healthy children attending day acre centers in lisbon, portugal. Microb Drug Resist 1999;5:19-29. [PubMed: 10332718]

13. Hudson I. The efficacy of intranasal mupirocin in the prevention of staphylococcal infections: a review of recent experience. J Hosp Infect 1994;28:235. [PubMed: 7852737]

14. Young R. Bacteriophage lysis: mechanism and regulation. Microbiol Rev 1992;56:430-481. [PubMed: 1406491]

15. Loeffler JM, Nelson D, Fischetti VA. Rapid killing of Streptococcus pneumoniae with a bacteriophage cell wall hydrolase. Science 2001;294:2170-2172. [PubMed: 11739958]

16. Nelson D, Chahalis P, Zhu S, Fischetti V. PlyC: The first multimeric bacteriophage lysin. Proc Natl Acad Sci. 2006 
17. Diaz E, Lopez R, Garcia JL. Chimeric phage-bacterial enzymes: a clue to the modular evolution of genes. Proc Natl Acad Sci USA 1990;87:8125-8129. [PubMed: 1978320]

18. Garcia P, Garcia JL, Garcia E, Sanchez-Puelles JM, Lopez R. Modular organization of the lytic enzymes of Streptococcus pneumoniae and its bacteriophages. Gene 1990;86:81-88. [PubMed: 2311937]

19. Loessner MJ. Bacteriophage endolysins- current state of research and applications. Current Opinion in Microbiology 2005;8:480-487. [PubMed: 15979390]

20. Pritchard DG, Dong S, Kirk MC, Cartee RT, Baker JR. LambdaSa1 and LambdaSa2 prophage lysins of Streptococcus agalactiae. Appl Environ Microbiol 2007;73:7150-7154. [PubMed: 17905888]

21. Navarre WW, Ton-That H, Faull KF, Schneewind O. Multiple enzymatic activities of the murein hydrolase from staphylococcal phage phi11. Identification of a D-alanyl-glycine endopeptidase activity. The Journal of Biological Chemistry 1999;274:15847-15856. [PubMed: 10336488]

22. Lopez R, Garcia E, Garcia P, Garcia JL. The pneumococcal cell wall degrading enzymes: a modular design to create new lysins? Microb Drug Resist 1997;3:199-211. [PubMed: 9185148]

23. Lopez R, Garcia JL, Garcia E, Ronda C, Garcia P. Structural analysis and biological significance of the cell wall lytic enzymes of Streptococcus pneumoniae and its bacteriophage. FEMS Microbiol Lett 1992;79:439-447. [PubMed: 1362174]

24. Garcia E, Garcia JL, Arraras A, Sanchez-Puelles JM, Lopez R. Molecular evolution of lytic enzymes of Streptococcus pneumoniae and its bacteriophages. Proc Natl Acad Sci USA 1988;85:914-918. [PubMed: 3422470]

25. Hermoso JA, Monterroso B, Albert A, Galan B, Ahrazem O, Garcia P, Martinez-Ripoli M, Garcia JL, Menendez M. Structural basis for selective recognition of pneumococcal cell wall by modular endolysin from phage Cp-1. Structure 2003;11:1239-1249. [PubMed: 14527392]

26. Loessner MJ, Kramer K, Ebel F, Scherer S. C-terminal domains of Listeria monocytogenes bacteriophage murein hydrolases determine specific recognition and high-affinity binding to bacterial cell wall carbohydrates. Mol Microbiol 2002;44:335-349. [PubMed: 11972774]

27. Weiss K, Laverdiere M, Lovgren M, Delorme J, Poirier L, Beliveau C. Group A Streptococcus carriage among close contacts of patients with invasive infections. Am J Epidemiol 1999;149:863868. [PubMed: 10221323]

28. Foley S, Bruttin A, Brussow H. Widespread distribution of a group I intron and its three deletion derivatives in the lysin gene of Streptococcus thermophilus bacteriophages. J Virol 2000;74:611618. [PubMed: 10623722]

29. Flaherty SO, Coffey A, Meaney W, Fitzgerald GF, Ross RP. Genome of staphylococcal phage K:a new lineage of Myoviridae infecting gram- positive bacteria with a low $\mathrm{G}+\mathrm{C}$ content. Journal of Bacteriolgy 2004;186(9):2862-2871.Ref Type: Generic

30. Nelson D, Schuch R, Zhu S, Tscherne DM, Fischetti VA. Genomic sequence of C1, the first streptococcal phage. Journal of Bacteriology 2003;185(11):3325-3332. [PubMed: 12754230]

31. Fernandez-Lopez M, Munoz-Adelantado E, Gillis M, Williams A, Toro N. Dispersal and evolution of the Sinorhizobium meliloti group II RmInt1 Intron in bacteria that interact with plants. Mol Biol Evol 2005;22:1518-1528. [PubMed: 15814827]

32. Tan K, Ong G, Song K. Introns in the cytolethal distending toxin gene of Actinobacillus Actinomycetemcomitans. J Bacteriol 2005;187:567-575. [PubMed: 15629928]

33. Jervis EJ, Haynes CA, Kilburn DG. Surface diffusion of cellulases and their isolated binding domains on cellulose. Journal of Biological Chemistry 1997;272:24016-24023. [PubMed: 9295354]

34. Identification of a broadly active phage lytic enzyme with lethal activity against antibiotic-resistant Enterococcus faecalis and Enterococcus faecium. Journal of Bacteriology 2004;186:4808-4812. [PubMed: 15231813]

35. Rashel M, Uchiyama J, Ujihara T, Uehara Y, Kuramoto S, Sugihara S, Yagyu K, Muraoka A, Sugai M, Hiramatsu K, Honke K, Matsuzaki S. Efficient elimination of multidrug-resistant Staphylococcus aureus by cloned lysin derived from bacteriophage phi MR11. J Infect Dis 2007;196:1237-1247. [PubMed: 17955443]

36. Sass P, Bierbaum G. Lytic activity of recombinant bacteriophage phi11 and phi12 endolysins on whole cells and biofilms of Staphylococcus aureus. Appl Environ Microbiol 2007;73:347-352. [PubMed: 17085695] 
37. O'Flaherty S, Coffey A, Meaney W, Fitzgerald GF, Ross RP. The recombinant phage lysin LysK has a broad spectrum of lytic activity against clinically relevant staphylococci, including methicillinresistant Staphylococcus aureus. J Bacteriol 2005;187:7161-7164. [PubMed: 16199588]

38. Clyne M, Birkbeck TH, Arbuthnott JP. Characterization of staphylococcal Y-lysin. J Gen Microbiol 1992;138:923-930. [PubMed: 1645129]

39. Sonstein SA, Hammel JM, Bondi A. Staphylococcal bacteriophage-associated lysin: a lytic agent active against Staphylococcus aureus. J Bacteriol 1971;107:499-504. [PubMed: 4255880]

40. Loeffler JM, Fischetti VA. Synergistic lethal effect of a combination of phage lytic enzymes with different activities on penicillin-sensitive and -resistant Streptococcus pneumoniae strains. Antimicrob Agents Chemother 2003;47:375-377. [PubMed: 12499217]

41. Eliopoulos, G.; Moellering, R. Antimicrobial combinations. In: Lorian, V., editor. Antibiotics in laboratory medicine. Baltimore, MD: Williams and Wilkins; 1991.

42. Jado I, Lopez R, Garcia E, Fenoll A, Casal J, Garcia P. Phage lytic enzymes as therapy for antiobioticresistant Streptococcus pneumoniae infection in a murine sepsis model. Journal of Antimicrobial Chemotherapy 2003;52:967-973. [PubMed: 14613958]

43. Djurkovic S, Loeffler JM, Fischetti VA. Synergistic killing of Streptococcus pneumoniae with the bacteriophage lytic enzyme Cpl-1 and penicillin or gentamicin depends on the level of penicillin resistance. Antimicrob Agents Chemother 2005;49:1225-1228. [PubMed: 15728935]

44. Cheng Q, Nelson D, Zhu S, Fischetti VA. Removal of group B streptococci colonizing the vagina and oropharynx of mice with a bacteriophage lytic enzyme. Antimicrobial Agents and Chemotherapy 2005;49:111-117. [PubMed: 15616283]

45. Walsh S, Shah A, Mond J. Improved Pharmacokinetics and reduced antibody reactivity of lysostaphin conjugated to polyethylene glycol. Antimicrob Agents Chemother 2003;47:554-558. [PubMed: 12543658]

46. Grandgirard D, Loeffler JM, Fischetti VA, Leib SL. Phage lytic enzyme cpl-1 for antibacterial therapy in experimental pneumococcal meningitis. J Infect Dis 2008;197:1519-1522. [PubMed: 18471063]

47. Entenza JM, Loeffler JM, Grandgirard D, Fischetti VA, Moreillon P. Therapeutic effects of bacteriophage Cpl-1 lysin against Streptococcus pneumoniae endocarditis in rats. Antimicrob Agents Chemother 2005;49:4789-4792. [PubMed: 16251333]

48. Kengatharan KM, De KS, Robson C, Foster SJ, Thiemermann C. Mechanism of gram-positive shock: identification of peptidoglycan and lipoteichoic acid moieties essential in the induction of nitric oxide synthase, shock, and multiple organ failure. J Exp Med 1998;188:305-315. [PubMed: 9670043]

49. Tuomanen E, Liu H, Hengstler B, Zak O, Tomasz A. The induction of meningeal inflammation by components of the pneumococcal cell wall. J Infect Dis 1985;151:859-868. [PubMed: 3989321]

50. Watanabe T, Morimoto A, Shiomi T. The fine structure and the protein composition of gamma phage of Bacillus anthracis. Can J Microbiol 1975;21:1889-1892. [PubMed: 811348]

51. Garcia P, Garcia E, Ronda C, Tomasz A, Lopez R. Inhibition of lysis by antibody aginst phageassociated lysin and requirement of choline residues in the cell wall for progeny phage release in Streptococcus pneumoniae. Curr Microbiol 1983;8:137-140. 


\section{Catalytic Domain Cell Binding Domain}

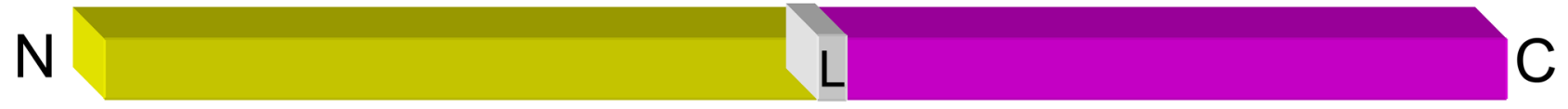

1. Endo- $\beta-\mathrm{N}$-acetylglucosaminidase

2. $\mathrm{N}$-acetylmuramidase

3. Endopeptidase

4. N-acetylmuramoyl-L-alanine amidase

5. y-D-glutaminyl-L-lysine endopeptidase
Binds to a cell wall substrate (usually a carbohydrate) that appears to be essential for bacterial survival

Figure 1. Basic structure of phage lytic enzymes

With one exception [16], the majority of the enzymes that have been characterized so far are built with two domains separated by a short linker (L): an N-terminal catalytic domain and a C-terminal cell binding domain ranging from $25-40 \mathrm{kDa}$ in size. The catalytic domain retains the activity to cleave one of the four major bonds in the bacterial peptidoglycan. Thus, they fall into one of five classes, either a glucosaminidase an $\mathrm{N}$-acetylmuramidase, an endopeptidase, an $\mathrm{N}$-acetylmuramoyl-L-alanine amidase or a $\gamma$-D-glutaminyl-L-lysine endopeptidase. In rare cases, lysins may have two or three different catalytic domains. The Cterminal half of the molecule binds to a substrate in the target bacterial cell wall (usually carbohydrate). Sequence comparisons of enzymes in the same enzyme class indicate that the catalytic region is highly conserved while the $\mathrm{C}$-terminal region is variable. 

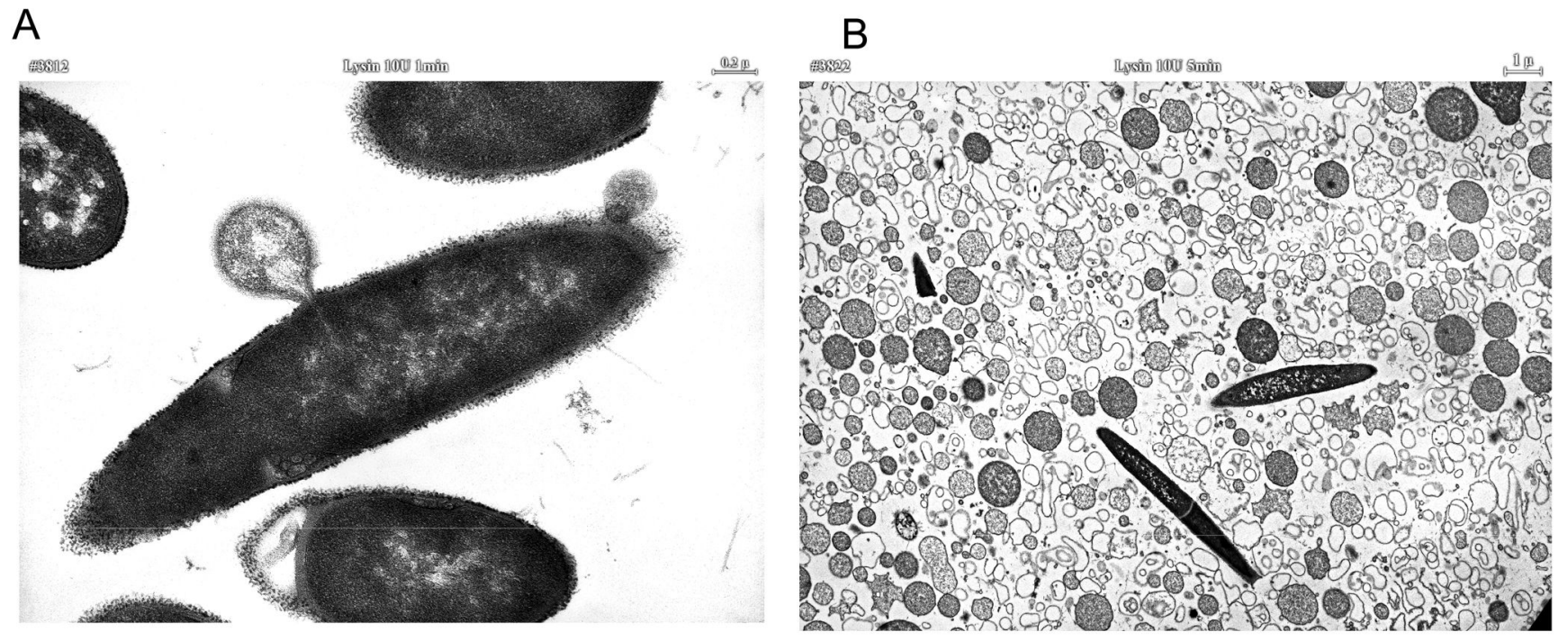

Figure 2. Electron microscopy of lysin treated bacilli

Thin section electron micrograph of B. cereus (RSVF) [9] after treatment with phage lytic enzyme PlyPH) [34]. A. High magnification of a bacillus exhibiting externalization of the cytoplasmic membrane after treatment with enzyme for 1 minute. B. Low magnification field of bacilli showing bacterial ghosts after 10 minutes of treatment with lysin. 


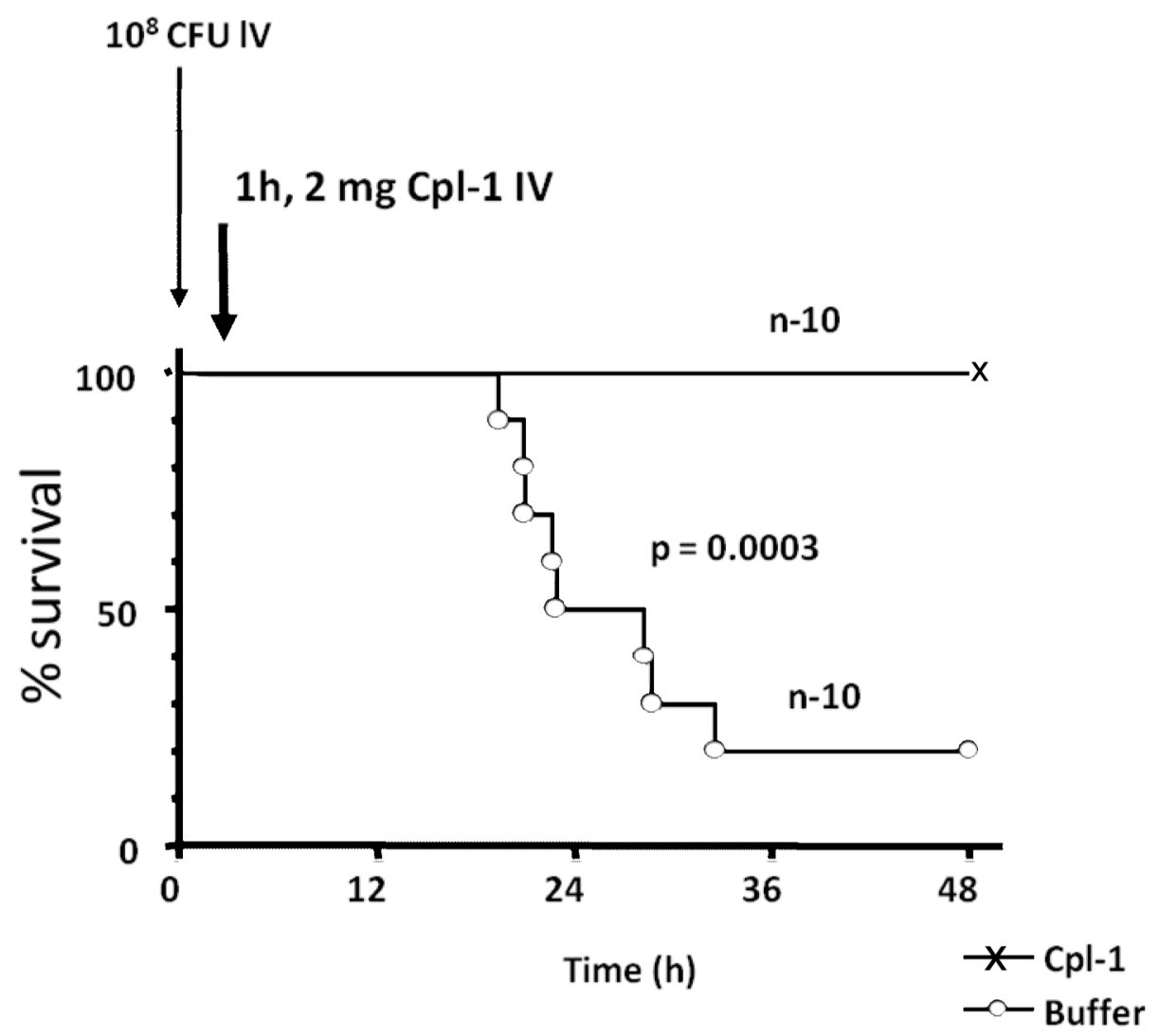

Figure 3. Survival of pneumococcal bacteremia after i.v. treatment with Cpl-1 A typical protection experiment in which mice were given $10^{8}$ pneumococci intravenously One hour later they were treated with Cpl-1 lysin by the same route and followed for 48 hrs. All mice treated with lysin survived while most of the control animals that received buffer died. 